\title{
HEAT CAPACITY AND VAPOR PRESSURE OF CRYSTALLINE BIS(BENZENE)CHROMIUM. THIRD-LAW ENTROPY COMPARISON AND THERMODYNAMIC EVIDENCE CONCERNING THE STRUCTURE OF BIS(BENZENE)CHROMIUM*
}

JOHN T. S. ANDREWS, EDGAR F. WESTRUM, JR.

Department of Chemistry, Unitersity of Michigan, Ann Arbor, Michigan (U.S.A.)

AND NIELS BJERRUM ${ }^{\star \star}$

Thermochemical Laboratory, University of Lund, Lund (Sweden)

(Received February 4th, 1969)

\section{SUMMARY}

Heat capacity measurements from 5 to $350^{\circ} \mathrm{K}$ and vapor pressure measurements on bis(benzene)chromium together with the published frequency assignments permit a correlation between the third-law and spectroscopic entropies. Neither thermal anomalies nor zero point entropy were found. The agreement is consistent with free rotation about the ring to metal bonds and $D_{6 h}$ symmetry for the molecule as proposed by Cotton. The thermodynamic functions for the crystal at $298.15^{\circ} \mathrm{K}$ are $53.52,54.07,26.77$, and $-27.30 \mathrm{cal} \cdot \mathrm{mole}^{-1 .}{ }^{\circ} \mathrm{K}^{-1}$ for the heat capacity, entropy, enthalpy function, and Gibbs function, respectively. The vapor pressure over the range 310 to $365^{\circ} \mathrm{K}$ is represented by $\log _{10} p(\mathrm{~mm})=27.42-5451 / T-5.535 \log _{10} T$, $\left(T\right.$ in ${ }^{\circ} \mathrm{K}$ ).

\section{INTRODUCTION}

The $\pi$-complexes of transition metals with aromatic molecules are sandwich compounds in which the aromatic ring may rotate about the ring-to-metal bond. We report here the results of a thermal investigation of bis(benzene)chromium undertaken to determine the magnitude of the energy barrier to this rotation of the rings, and also to ascertain the possible presence of thermodynamic evidence for a distorted ring structure in this compound. Theoretical arguments ${ }^{1,2}$ suggest that the rings might be trigonally distorted (alternating short and long $\mathrm{C}-\mathrm{C}$ bonds as in a Kekule benzene structure) and Jellinek ${ }^{3}$ has reported an X-ray diffractional analysis consistent with this distortion and $D_{3 d}$ symmetry for the molecule. Later workers (Cotton, Dollase and Wood $)^{4}$ in an independent $X$-ray investigation reported a molecular symmetry of $D_{6 h}$ with hexagonally symmetric benzene rings. The existence of ring distortion would be of thermodynamic interest, for it would imply $(a)$ that the distorted molecules might fit into the crystal lattice in two distinct orientations related

* This research was supported in part by the Division of Research of the U.S. Atomic Energy Commission. $\star \star$ Present address: The Technical University of Denmark, Lyngby, Denmark. 
one to the other by $60^{\circ}$ rotation about the threefold axis of the molecule, and (b) that the resulting crystal phase might be ordered or disordered with respect to these orientations. Such a disordered phase would have $R \cdot \ln 2$ more entropy than the ordered one. Jellinek suggested ${ }^{5}$ that the discrepancy in the $\mathrm{X}$-ray results would be explained if he had, by chance, investigated an ordered crystal, while Cotton et al. had a disordered crystal and had therefore reported a structure based on the average of the two orientations.

We measured the heat capacity from 5 to $350^{\circ} \mathrm{K}$ and the vapor pressure from 323 to $363^{\circ} \mathrm{K}$ of bis(benzene)chromium to look for direct indications of an orderdisorder transition. These data also were used to compute the gas phase entropy which was then compared with that calculated by statistico-mechanical methods to check the possibility of a residual zero point entropy of $R \cdot \ln 2$. This would be expected if the supposedly disordered crystal phase had persisted below the temperature range of the heat capacity measurements. The entropy comparison also provides information on the energy barrier to ring rotation.

\section{EXPERIMENTAL}

\section{Preparation and characterization of the sample}

The bis(benzene)chromium sample was prepared at Lund with the method advocited by Fischer ${ }^{6}$, and was purified, as he recommended, by washing with ether followed by sublimation under high vacuum at $160^{\circ}$. The sample then consisted of well-formed, blunt-acicular, lustrous-black crystals, of length 0.5 to $3 \mathrm{~mm}$.

The chromium content of this material was determined (after decomposition with hydrogen peroxide and nitric acid and oxidation with persulfuric acid) by titration against $\mathrm{Fe}^{\mathrm{II}}$. Two series of triplicated analyses were performed, and gave mean chromium contents of $24.81 \%$ and $24.94 \%$ (theoretical value $24.98 \%$ ). Pyrolysis of a portion of the sample at $450^{\circ}$ showed that it was possible to decompose bis(benzene) chromium to about $25 \%$ chromium, $73 \%$ benzene, $2 \%$ carbon, and $0.2 \%$ hydrogen. Slight traces of other organic decomposition products were found by GLC. The melting point of the sample was found to be $285.6^{\circ}$; this agrees well with the literature value ${ }^{6}$ of $284.5^{\circ}$. The sample was sealed in glass under vacuum for transportation to Ann Arbor and was handled only in a nitrogen-filled dry box.

\section{Calorimetric procedure}

The calorimetric sample (mass $20.5773 \mathrm{~g}$ in vacuo) was loaded mechanically into the goldplated copper calorimeter (iaboratory designation W-39) with an internal volume of $22.7 \mathrm{~cm}^{3}$ and a mass of $13.11 \mathrm{~g}$ including the closure. A helium pressure of $44 \mathrm{~mm}$ at $300^{\circ} \mathrm{K}$ was introduced into the calorimeter to facilitate thermal equilibration, and the calorimeter was then sealed with an annealed gold gasket and screw cap. Heat capacity measurements were made in the Mark II adiabatic cryostat ${ }^{7}$. Temperatures were measured with a $25-\mathrm{ohm}$, capsule-type, platinum-resistance thermometer (laboratory designation A-5) situated within the axial well of the calorimeter. These temperaturcs are believed to be in accord with the thermodynamic temperature scale within $0.03^{\circ}$ from 10 to $90^{\circ} \mathrm{K}$, and within $0.04^{\circ}$ from 90 to $350^{\circ} \mathrm{K}$. The heat capacity of the empty calorimeter was determined in a separate experimental series, small corrections being applied for differences between the loaded and empty 
calorimeter in the quantities of helium and thermal-conduction (Apiezon T) grease. Measurements of mass, voltage, current, time and temperature were referred to calibrations or standardizations performed by the National Bureau of Standards.

\section{Vapor pressure determinations}

The vapor pressure of bis(benzene)chromium was determined on a portion of the calorimetric sample by the Knudsen effusion technique. The apparatus was similar to that of Edwards and Kington ${ }^{8}$. The effusion cell was of copper $1.25 \mathrm{~cm}$ in diameter and fitted with a screw cap. The effusion hole with a radius of $0.417 \mathrm{~mm}$ was drilled in $0.0173 \mathrm{~mm}$ thick copper foil soldered to this cap. The diameter of the hole was measured with a metallurgical measuring microscope, the area of the hole being $(0.547 \pm 0.001) \mathrm{mm}^{2}$. A water thermostat, controlled by a Leeds and Northrup three action proportional controller and a nickel resistance thermometer, was used to obtain temperature control better than $\pm 0.003^{\circ}$ over the period of the runs. Temperatures were measured with a Dymec digital quartz thermometer, which had been calibrated against a $25-\mathrm{ohm}$, platinum-resistance thermometer.

The basic expression for relating the rate of material loss from the effusion cell with the equilibrium vapor pressure was derived by Langmuir (given, for example, by Thomson ${ }^{9}$ ). This expression holds only in the limits of an effusion hole of zero length, and a mean free path of the molecule much greater than the diameter of the effusion hole. In order to correct for the finite length of the hole, a correction factor given by Knudsen ${ }^{10}$ is applied, and a further factor (due to Hiby and Pahl ${ }^{11}$ ) adjusts the vapor pressures at high pressures where the mean free path is no longer large compared with the diameter $d$ of the effusion hole. In this research, the mean free path varied from approximately $d$ to $100 d$. This question is treated more thoroughly by Edwards and Kington ${ }^{8}$ and by Carman ${ }^{12}$.

The pressure is then calculated according to the relationship:

$$
p=\frac{g}{t \cdot A} \cdot\left(\frac{2 \pi R \cdot T}{M}\right)^{t} \cdot\left(\frac{8 r+3 l}{8 r}\right) \cdot\left(\frac{1}{1+0.48 r / 2 \lambda}\right)
$$

$\lambda=$ Mean free path $\left[\lambda=k \cdot T /\left(\sqrt{ } 2 \pi \sigma^{2} \cdot p\right)\right](\mathrm{cm}), p=$ pressure $\left(\right.$ dyne $\left.\cdot \mathrm{cm}^{-2}\right), g=$ weight loss in run (g), $t=$ duration of run (sec), $A=$ area of effusion hole $\left(\mathrm{cm}^{2}\right), R=$ gas constant $\left(\mathrm{erg} \cdot{ }^{\circ} \mathrm{K}^{-1} \cdot \mathrm{mole}^{-1}\right), T=$ temperature of run $\left({ }^{\circ} \mathrm{K}\right), M=$ molecular weight $\left(\mathrm{g} \cdot \mathrm{mole}^{-1}\right)$, $r=$ radius of effusion hole $(\mathrm{cm}), l=$ length of effusion hole $(\mathrm{cm}), k=$ Boltzmann constant $\left(\mathrm{erg} \cdot{ }^{\circ} \mathrm{K}^{-1}\right), \sigma=$ collision diameter of molecule $(\mathrm{cm})=6.99 \times 10^{-8}(\mathrm{~cm})(\mathrm{twice}$ the geometric mean of the principal radii).

RESULTS

The experimental heat capacity points are presented in chronological order in Table 1 and graphically in Fig. 1. The temperature increments employed in their determination may usually be inferred from the difference between adjacent mean temperatures. The values have been adjusted for curvature occasioned by the finite temperature differences employed and are based upon the defined thermochemical calorie equal to $4.1840 \mathrm{~J}$, an ice point of $273.15^{\circ} \mathrm{K}$, and a gram formula mass for bis(benzene)chromium of 208.225. The heat capacities have a standard deviation of about $0.5 \%$ from 10 to $15^{\circ} \mathrm{K}$ which rapidly decreases to $0.1 \%$ at higher temperatures. 
TABLE 1

EXPERLMENTAL HEAT CAPACITY OF BLS(BENZENE)CHROMIUM ${ }^{a}$

\begin{tabular}{|c|c|c|c|c|c|}
\hline$T$ & $c_{p}$ & $\bar{T}$ & $c_{p}$ & $\bar{T}$ & $c_{p}$ \\
\hline \multirow{2}{*}{\multicolumn{2}{|c|}{ Series I }} & 243.30 & 42.83 & 22.54 & 4.96 \\
\hline & & 252.45 & 44.60 & 25.30 & 5.94 \\
\hline 93.38 & 17.70 & 261.88 & 46.47 & 28.59 & 6.99 \\
\hline 98.44 & 18.36 & 271.04 & 48.25 & 32.06 & 8.00 \\
\hline 108.46 & 19.70 & 279.94 & 49.99 & 35.53 & 8.91 \\
\hline 120.15 & 21.36 & 288.61 & 51.63 & 38.92 & 9.69 \\
\hline 126.47 & 22.30 & 297.05 & 53.28 & 42.66 & 10.47 \\
\hline 134.42 & 23.51 & 305.30 & 54.90 & 47.01 & 11.30 \\
\hline 143.94 & 25.00 & 313.61 & 56.50 & 51.86 & 12.11 \\
\hline 154.00 & 26.63 & 322.01 & 58.02 & 56.88 & 12.88 \\
\hline 163.55 & 28.21 & 330.21 & 59.66 & 61.49 & 13.58 \\
\hline \multirow[t]{2}{*}{172.70} & 29.77 & 338.24 & 61.22 & 66.46 & 14.25 \\
\hline & & 346.32 & 62.80 & & \\
\hline \multicolumn{2}{|l|}{ Series $I I$} & \multirow{2}{*}{\multicolumn{2}{|c|}{ Series IV }} & \multicolumn{2}{|c|}{ Series VI } \\
\hline 163.95 & 28.26 & & & 67.78 & 14.42 \\
\hline 173.46 & 20.89 & 6.26 & 0.16 & 74.88 & 15.30 \\
\hline 182.54 & 31.48 & 6.81 & 0.21 & 81.45 & 16.19 \\
\hline 191.27 & 33.09 & 7.68 & 0.32 & 87.59 & 17.04 \\
\hline 199.69 & 34.61 & 8.64 & 0.46 & 93.42 & 17.74 \\
\hline 207.83 & 36.10 & 9.70 & 0.69 & 95.02 & 17.92 \\
\hline 215.72 & 37.60 & 10.76 & 0.92 & \multicolumn{2}{|c|}{$\Delta H$ Run A } \\
\hline 223.38 & 39.06 & 11.82 & 1.16 & \multicolumn{2}{|c|}{$\Delta H$ Run B } \\
\hline 230.83 & 40.47 & & & 285.97 & 51.16 \\
\hline 238.08 & 41.87 & Series $V$ & & 294.10 & 52.77 \\
\hline \multirow[t]{2}{*}{245.15} & 43.21 & 11.68 & 1.14 & 302.00 & 54.26 \\
\hline & & 12.82 & 1.47 & 310.29 & 55.80 \\
\hline \multicolumn{2}{|l|}{ Series III } & 14.03 & 1.85 & 318.62 & 57.44 \\
\hline 205.95 & 35.74 & 15.35 & 2.30 & 326.78 & 58.93 \\
\hline 215.81 & 37.59 & 16.78 & 2.84 & 334.77 & 60.85 \\
\hline 225.28 & 39.42 & 18.40 & 3.43 & 342.61 & 62.26 \\
\hline 234.43 & 41.19 & 20.28 & 4.12 & 348.04 & 62.88 \\
\hline
\end{tabular}

anits: cal, mole, ${ }^{\circ} \mathrm{K}$.

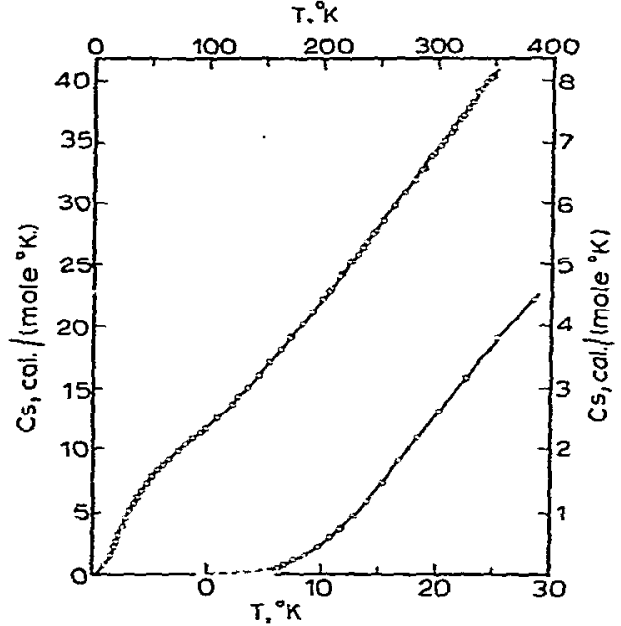

Fig. 1. The heat capacity of bis(benzene)chromium.

J. Organometal. Chem, 17 (1969) 293-302 
TABLE 2

THERMODYNAMIC FUNCTIONS OF BIS(BENZENE)CHROMIUM ${ }^{\circ}$

\begin{tabular}{|c|c|c|c|c|c|}
\hline$T$ & $c_{p}$ & $s^{\infty}$ & $H^{\circ}-H_{0}^{\circ}$ & $\left(H^{\circ}-H_{\mathrm{o}}^{\circ}\right) / T$ & $-\left(G^{\circ}-H_{0}^{\circ}\right) / T$ \\
\hline 5 & 0.087 & 0.029 & 0.109 & 0.022 & 0.007 \\
\hline 10 & 0.732 & 0.234 & 1.768 & 0.177 & 0.057 \\
\hline 15 & 2.180 & 0.783 & 8.783 & 0.586 & 0.198 \\
\hline 20 & 4.025 & 1.659 & 24.230 & 1.212 & 0.448 \\
\hline 25 & 5.834 & 2.755 & 48.958 & 1.958 & 0.797 \\
\hline 30 & 7.419 & 3.963 & 82.194 & 2.740 & 1223 \\
\hline 35 & 8.772 & 5.211 & 122.76 & 3.508 & 1.704 \\
\hline 40 & 9.928 & 6.460 & 169.59 & 4.240 & 2.220 \\
\hline 45 & 10.928 & 7.688 & 221.8 & 4.929 & 2.760 \\
\hline 50 & 11.81 & 8.886 & 278.7 & 5.573 & 3.313 \\
\hline 60 & 13.35 & 11.179 & 404.6 & 6.744 & 4.435 \\
\hline 70 & 14.71 & 13.340 & 545.0 & 7.786 & 5.554 \\
\hline 80 & 16.00 & 15.390 & 698.7 & 8.733 & 6.656 \\
\hline 90 & 17.28 & 17.349 & 865.1 & 9.612 & 7.786 \\
\hline 100 & 18.58 & 19.236 & 1044.4 & 10.444 & 8.792 \\
\hline 110 & 19.93 & 21.07 & 1236.9 & 11.244 & 9.826 \\
\hline 120 & 21.34 & 22.86 & 1443.2 & 12.03 & 10.84 \\
\hline 130 & 22.83 & 24.63 & 1664 & 12.80 & 11.83 \\
\hline 140 & 24.37 & 26.38 & 1900 & 13.57 & 12.81 \\
\hline 150 & 25.97 & 28.11 & 2152 & 14.34 & 13.77 \\
\hline 160 & 27.62 & 29.84 & 2419 & 15.12 & 14.72 \\
\hline 170 & 29.31 & 31.57 & 2704 & 15.91 & 15.66 \\
\hline 180 & 31.04 & 33.29 & 3006 & 16.70 & 16.59 \\
\hline 190 & 32.82 & 35.02 & 3325 & 17.50 & 17.52 \\
\hline 200 & 34.65 & 36.75 & 3662 & 18.31 & 18.44 \\
\hline 210 & 36.52 & 38.48 & 4018 & 19,13 & 19.35 \\
\hline 220 & 38.41 & 40.22 & 4393 & 19.97 & 20.26 \\
\hline 230 & 40.31 & 41.97 & 4786 & 20.81 & 21.16 \\
\hline 240 & 42.23 & 43.73 & 5199 & 21.66 & 22.07 \\
\hline 250 & 44.15 & 45.49 & 5631 & 22.52 & 22.97 \\
\hline 260 & 46.09 & 47.26 & 6082 & 23.39 & 23.87 \\
\hline 270 & 48.03 & 49.04 & 6553 & 24.27 & 24.77 \\
\hline 273.15 & 48.65 & 49.60 & 6705 & 24.55 & 25.05 \\
\hline 280 & 49.99 & 50.82 & 7043 & 25.15 & 25.67 \\
\hline 290 & 51.94 & 52.61 & 7552 & 26.04 & 26.57 \\
\hline 298.15 & 53.52 & 54.07 & 7982 & 26.77 & 27.30 \\
\hline 300 & 53.88 & 54.40 & 8082 & 26.94 & 27.46 \\
\hline 310 & 55.78 & 56.20 & 8630 & 27.84 & 28.36 \\
\hline 320 & 57.67 & 58.00 & 9197 & 28.74 & 29.26 \\
\hline 330 & 59.59 & 59.80 & 9783 & 29.65 & 30.16 \\
\hline 340 & 61.57 & 61.61 & 10389 & 30.56 & 31.06 \\
\hline 350 & 63.46 & 63.43 & 11015 & 31.47 & 31.96 \\
\hline
\end{tabular}

${ }^{\circ}$ Units: cal, mole, ${ }^{\circ} \mathrm{K}$.

The heat capacities in Table 2 were obtained from a smooth polynomial expression fitted by computer through the experimental points using least squares criteria. The extrapolation below $5^{\circ} \mathrm{K}$ was made using the Debye limiting law, fit from a plot of 
TABLE 3

VAPOR PRESSURE OF BIS(BENZENE)CHROMIUM

\begin{tabular}{ll}
\hline$T(\mathrm{~K})$ & $p \times 10^{3}(\mathrm{~mm})$ \\
\hline 323.227 & 0.456 \\
323.392 & 0.478 \\
323.954 & 0.485 \\
328.300 & 0.781 \\
335.680 & 1.639 \\
338.877 & 2.119 \\
339.168 & 2.25 \\
343.969 & 3.46 \\
348.320 & 5.17 \\
353.840 & 8.09 \\
358.230 & 11.68 \\
360.670 & 14.18 \\
363.275 & 17.22 \\
\hline
\end{tabular}

$C_{p} / T^{-} v s . T^{2}$. The thermodynamic functions in this table were obtained by integration of this curve, and are considered to have a precision corresponding to a standard deviation of $0.1 \%$ above $100^{\circ} \mathrm{K}$. The entropies and Gibbs energies have not been adjusted for nuclear spin or isotopic mixing contributions, and are therefore practical chemical thermodynamic quantities.

The vapor pressure results are presented in Table 3 and in Fig. 2. For comparison, the results of Cordes and Schreiner ${ }^{13}$, and Fischer and Schreiner ${ }^{14}$ are plotted also. Least squares analysis was used to fit the function to the data ( $p$ in $\mathrm{mm}$, $T$ in ${ }^{\circ} \mathrm{K}$ ):

$$
\log _{10} p=A+B / T+C \cdot \log _{10} T \text {. }
$$

The first two coefficients are: $A=(27.42 \pm 0.05), B=(-5451 \pm 17.7)^{\circ} \mathrm{K}$. The value of $C$ was constrained to that calculated from the difference in heat capacity between the

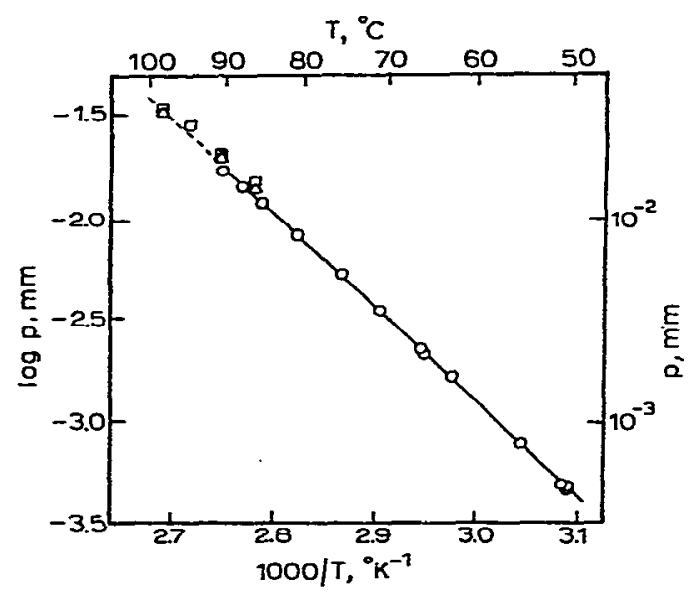

Fig. 2. The vapor presslire of bis(benzene)chromium as a function of temperature. The $O$ represent the data of this research, $\square$ those of Cordes and Schreiner ${ }^{14}, \Delta$ those of Fischer and Schreiner ${ }^{15}$.

J. Organometal. Chem., 17 (1969) 293-302 
crystal and gas phases $(-5.535)$. The standard deviations of the coefficients were calculated by the procedure described by Baird ${ }^{15}$.

The enthalpy of vaporization, $\Delta H_{\text {vap }}$, and hence the entropy of vaporization, $\Delta S_{\text {vap }}$, may then be expressed as a function of temperature:

$$
\begin{aligned}
& \Delta H_{\text {vap }}=(24.94 \pm 0.08)-0.011 T\left(\mathrm{kcal} \cdot \mathrm{mole}^{-1}\right) \\
& \Delta S_{\text {vap }}=(24940 \pm 80) / T-11\left(\mathrm{cal} \cdot \mathrm{mole}{ }^{-1} \cdot{ }^{\circ} \mathrm{K}^{-1}\right)
\end{aligned}
$$

The entropy of gaseous bis(benzene)chromium was calculated as a function of temperature, from the structural information of Haaland ${ }^{16}$ (obtained by electron diffraction of the gas), and the frequency assignment of Fritz, Lüttke, Stammreich, and Forniers ${ }^{17}$. The internal rotation was assumed to be free, and the usual approximations of the rigid-rotor harmonic oscillator model were employed (overall symmetry number 12). The frequencies employed in the calculation are listed in Table 4

TABLE 4

\begin{tabular}{|c|c|c|c|c|c|c|c|c|}
\hline $\begin{array}{l}\text { Benzene } \\
\text { symmetry } \\
\text { species }^{d}\end{array}$ & $\begin{array}{l}\text { Benzene } \\
\text { frequency } \\
\text { number }\end{array}$ & $\begin{array}{l}\text { Benzene } \\
\text { frequency } \\
\text { (ref. 19) }\end{array}$ & $\begin{array}{l}\text { BBC }^{b} \\
\text { symmetry } \\
\text { species }\end{array}$ & $\begin{array}{l}\mathrm{BBC} \\
\text { frequency } \\
\text { number }\end{array}$ & $\begin{array}{l}\text { BBC } \\
\text { frequency } \\
\text { (ref. 17) }\end{array}$ & $\begin{array}{l}\mathrm{BBC}^{+} \mathrm{I}^{-c} \\
\text { frequency } \\
\text { (ref. 17) }\end{array}$ & $\begin{array}{l}\mathrm{BBC} \\
\text { frequency } \\
\text { (ref. 18) }\end{array}$ & $\begin{array}{l}\text { Frequency } \\
\text { selected } \\
\text { for } \mathrm{BBC}\end{array}$ \\
\hline$A_{10}$ & $\begin{array}{l}1 \\
2\end{array}$ & $\begin{array}{l}995.4 \\
3073\end{array}$ & $\begin{array}{l}\left\{\begin{array}{l}A_{1 q} \\
A_{2 u}\end{array}\right. \\
\left\{\begin{array}{l}A_{1 g} \\
A_{2 u}\end{array}\right.\end{array}$ & $\begin{array}{l}1 \mathrm{~s} \\
1 \text { as } \\
2 \mathrm{~s} \\
2 \mathrm{as}\end{array}$ & $\begin{array}{r}971 \\
3037\end{array}$ & $\begin{array}{r}973 \\
972 \\
3095 \\
3040\end{array}$ & 970 & $\begin{array}{r}972 \\
971 \\
3092 \\
3037\end{array}$ \\
\hline$A_{2 g}$ & 3 & 1350 & $\left\{\begin{array}{l}A_{2 g} \\
A_{12}\end{array}\right.$ & $\begin{array}{l}3 \mathrm{~s} \\
3 \text { as }\end{array}$ & & & & $\begin{array}{l}1350 \\
1350\end{array}$ \\
\hline$B_{2 g}$ & $\begin{array}{l}4 \\
5\end{array}$ & $\begin{array}{l}707 \\
990\end{array}$ & $\begin{array}{l}\left\{\begin{array}{l}B_{2 g} \\
B_{1 \mu}\end{array}\right. \\
\left\{\begin{array}{l}B_{1 g} \\
B_{1 \mu}\end{array}\right.\end{array}$ & $\begin{array}{l}4 \mathrm{~s} \\
4 \text { as } \\
5 \mathrm{~s} \\
5 \text { as }\end{array}$ & & (950) & & $\begin{array}{l}707 \\
707 \\
950\end{array}$ \\
\hline$E_{g}^{+}$ & $\begin{array}{l}6 \\
7 \\
8 \\
9\end{array}$ & $\begin{array}{l}608.0 \\
3056 \\
1596 \\
1178\end{array}$ & $\begin{array}{l}\left\{\begin{array}{l}E_{q}^{+} \\
E_{u}^{+}\end{array}\right. \\
\left\{\begin{array}{l}E_{g}^{+} \\
E_{u}^{+}\end{array}\right. \\
\left\{\begin{array}{l}E_{g}^{+} \\
E_{u}^{+}\end{array}\right. \\
\left\{\begin{array}{l}E_{g}^{+} \\
E_{u}^{+}\end{array}\right.\end{array}$ & $\begin{array}{l}6 \mathrm{~s} \\
6 \text { as } \\
7 \mathrm{~s} \\
7 \text { as } \\
8 \mathrm{~s} \\
8 \text { as } \\
9 \mathrm{~s} \\
9 \text { as }\end{array}$ & & $\begin{array}{c}616 \\
(630) \\
3074 \\
1620 \\
1148\end{array}$ & & $\begin{array}{r}616 \\
630 \\
3074 \\
3056 \\
1620 \\
1599 \\
1148 \\
1178\end{array}$ \\
\hline$E_{g}^{-}$ & 10 & 846 & $\left\{\begin{array}{l}E_{\mathrm{g}}^{-} \\
E_{\mathrm{w}}^{-}\end{array}\right.$ & $\begin{array}{l}10 \mathrm{~s} \\
10 \mathrm{as}\end{array}$ & 833 & $\begin{array}{l}805 \\
857\end{array}$ & 1014 & $\begin{array}{l}800 \\
833\end{array}$ \\
\hline$A_{24}$ & 11 & 674.0 & $\left\{\begin{array}{l}A_{2 u} \\
A_{1 n}\end{array}\right.$ & $\begin{array}{l}11 \mathrm{~s} \\
11 \text { as }\end{array}$ & 794 & $\begin{array}{l}795 \\
790\end{array}$ & 796 & $\begin{array}{l}794 \\
796\end{array}$ \\
\hline$B_{1 L}$ & $\left\{\begin{array}{l}12 \\
13\end{array}\right.$ & $\begin{array}{l}1010 \\
3057\end{array}$ & $\begin{array}{l}\left\{\begin{array}{l}B_{14} \\
B_{2 \vartheta}\end{array}\right. \\
\left\{\begin{array}{l}B_{14} \\
B_{2 \theta}\end{array}\right.\end{array}$ & $\begin{array}{l}12 \mathrm{~s} \\
12 \text { as } \\
13 \mathrm{~s} \\
13 \text { as }\end{array}$ & & & & $\begin{array}{l}1010 \\
1010 \\
3057 \\
3057\end{array}$ \\
\hline
\end{tabular}

FREQUENCY ASSIGNMENT FOR BIS(BENZENE)CHROMIUM ${ }^{\circ}$ 


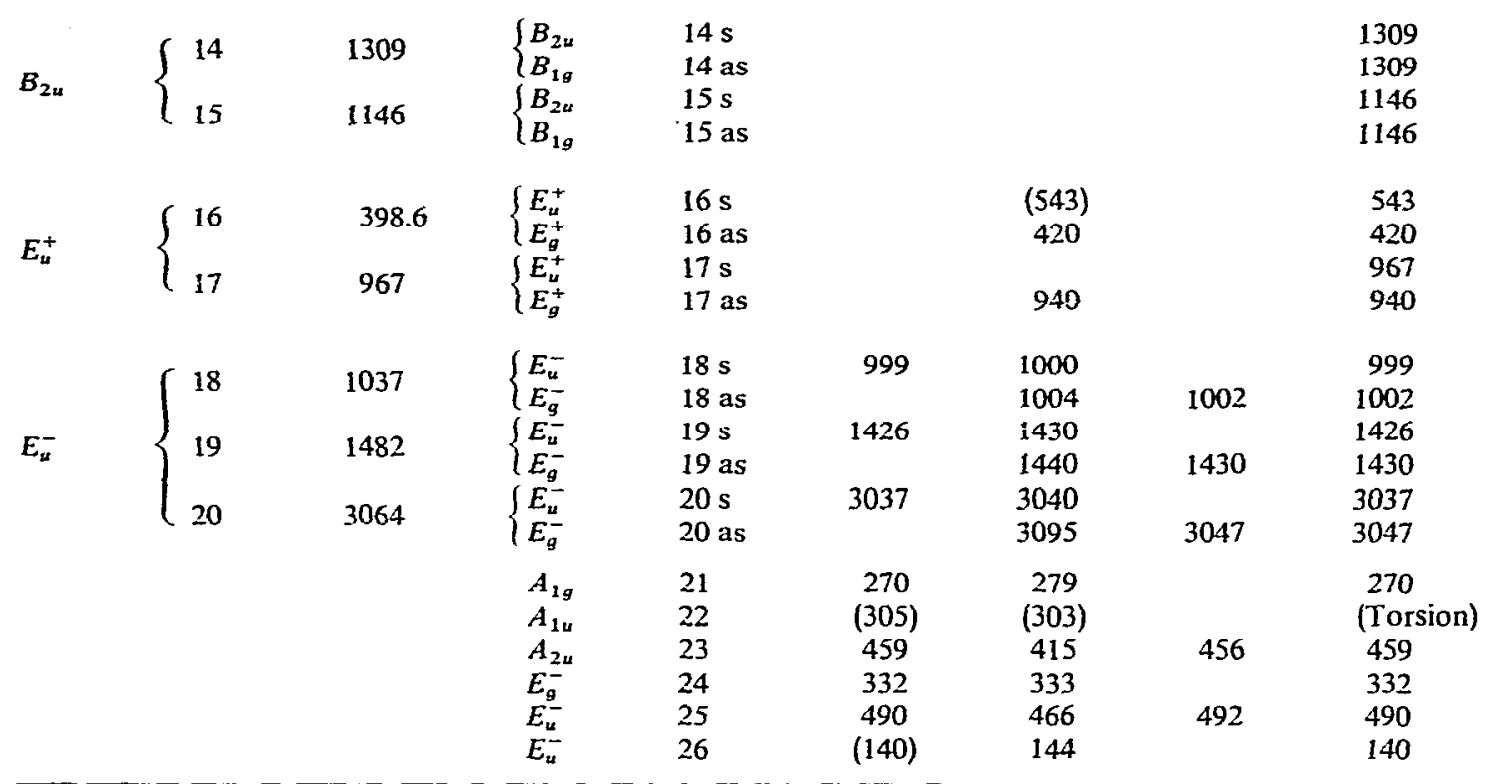

${ }^{a}$ Units: $\mathrm{cm}^{-1} .{ }^{b} \mathrm{BBC}$ : bis(benzene)chromium. ${ }^{c} \mathrm{BBC}^{+} \mathrm{I}^{-}$: bis(benzene)chromium iodide. ${ }^{d}$ The frequencies of the $E$ species are doubly degenerate.

\section{TABLE 5}

SPECTROSCOPIC ENTROPY OF BIS(BENZENE)CHROMIUM ${ }^{a}$

\begin{tabular}{lllllr}
\hline$T$ & $S_{\text {trans }}^{\circ}$ & $S_{\text {rot }}$ & $S_{\text {ir }}$ & $S_{\text {vib }}$ & \multicolumn{1}{c}{$S_{\text {tot }}^{\text {oo }}$} \\
\hline 298.15 & 41.91 & 25.25 & 5.61 & 20.10 & 92.87 \\
320 & 42.26 & 25.47 & 5.68 & 22.75 & 96.16 \\
350 & 42.70 & 25.73 & 5.76 & 26.48 & 100.67
\end{tabular}

- Units : cal, mole, ${ }^{\circ} \mathrm{K}$.

TABLE 6

ENTROPY COMPARISON FOR GASEOUS BIS(BENZENE)CHROMIUM ${ }^{a}$

\begin{tabular}{lllllll}
\hline$T$ & $S^{\circ}(\mathrm{c})^{b}$ & $\Delta S_{\text {vap }}{ }^{b}$ & $\Delta S_{\text {comp }}{ }^{d}$ & \multicolumn{1}{l}{$\begin{array}{l}S^{\circ}(\mathrm{g}) \\
\text { (3rd law) }\end{array}$} & \multicolumn{1}{l}{$\begin{array}{l}S^{\circ}(\mathrm{g})^{e} \\
\text { (spectro) }\end{array}$} & $S^{\circ}-S^{\prime o}$ \\
\hline 298.15 & 54.07 & & & & 92.87 & \\
310 & 56.20 & 69.46 & -31.27 & 94.39 & 94.64 & -0.25 \\
320 & 58.00 & 66.95 & -29.10 & 95.85 & 96.16 & -0.31 \\
330 & 59.80 & 64.58 & -27.08 & 97.30 & 97.66 & -0.36 \\
340 & 61.61 & 62.36 & -25.18 & 98.79 & 99.17 & -0.38 \\
350 & 63.43 & 60.27 & -23.40 & 100.30 & 100.67 & -0.37 \\
& \pm 0.06 & \pm 0.23 & \pm 0.14 & \pm 0.28 & \pm 0.3 & $\pm 0.4^{\delta}$ \\
\hline
\end{tabular}

${ }^{a}$ Units: cal, mole, ${ }^{\circ} \mathrm{K} .{ }^{b}$ Standard entropy of the crystal. ${ }^{\circ} \Delta S_{\mathrm{vap}}$ entropy of vaporization at $T$. ${ }^{d} \Delta S_{\text {comp }}$ entropy of compression of the gas from the saturation pressure to the standard pressure of one atm. e For the "free" rotator. $\mathcal{J}$ The precision indices are standard deviations. 
and frequencies for those vibrations not assigned by Fritz et al. were estimated by comparison with data of Snyder ${ }^{18}$ on bis(benzene)chromium and of Calloman, Dunn, and Mills ${ }^{19}$ on benzene. Contributions to the spectroscopic entropy of bis(benzene)chromium are listed for selected temperatures in Table 5, in which the total entropy is the sum of the entropies due to translation, rotation, internal rotation, and vibration $\left(S_{\mathrm{tot}}^{\circ}=S_{\text {trans }}^{\circ}+S_{\mathrm{rot}}+S_{\mathrm{ir}}+S_{\mathrm{vib}}=S^{\circ}(\mathrm{g})\right)$.

A comparison of the entropy calculated for the gas phase $\left[S^{\prime \circ}(\mathrm{g})\right]$ with that computed from the heat capacity and vapor pressure results by means of the third law $\left[S^{\circ}(\mathrm{g})=S^{\circ}(\mathrm{c})+\Delta S_{\text {vap }}+\Delta S_{\text {comp }}\right]$ is presented in Table 6.

\section{DISCUSSION}

The spectroscopic or statistical entropy calculated for bis(benzene)chromium with the assumption that the benzene rings are not distorted (i.e., that the symmetry number is 12) listed in Table 6 agrees with the 3rd law value near $350^{\circ} \mathrm{K}$ to within the resultant standard deviation $\left(0.4 \mathrm{cal} \cdot \mathrm{mole}^{-1.0} \mathrm{~K}^{-1}\right)$ of the two entropy evaluations. As for ferrocene ${ }^{23}$, the precision index is too large to exclude the possibility of a small barrier to internal rotation (i.e., $<1 \mathrm{kcal} / \mathrm{mole}$ ). Inclusion of such a barrier would improve the fit of the spectroscopic and third-law entropies. However, if the molecule is distorted in the manner postulated by Jellinek ${ }^{5}$ (molecular symmetry $D_{3 d}$ ), the symmetry number is six, and the spectroscopic entropy should be $R \cdot \ln 2$ (or $R \cdot \ln 12-R \cdot \ln 6),\left(=1.38 \mathrm{cal} \cdot \mathrm{mole}^{-1 .{ }^{\circ}} \mathrm{K}^{-1}\right)$ greater than that of the undistorted molecule. The experimental third-law results are in agreement with the spectroscopic entropy for undistorted molecules; addition of $R \cdot \ln 2$ to the experimental entropy would be required to achieve agreement with the spectroscopic entropy for the gas of distorted molecules.

Jellinek ${ }^{5}$ showed that if the molecule is distorted, then ordered and disordered crystal phases may exist, and he postulated (as noted above) that X-ray diffraction analysis had been done on both phases. We found no evidence of a phase transition in the heat capacity measurements, and conclude that the phase existing at $350^{\circ} \mathrm{K}$ is also stable at least as low as $5^{\circ} \mathrm{K}$. If we assume that the molecule is distorted and that we made measurements on the disordered phase, then the absence of a transition shows that the disorder was "frozen" into our sample, and $R \cdot \ln 2$ zero point entropy should be added to the third-law entropy. In this case, the third-law and spectroscopic entropies (for the distorted molecule) would be in agreement. If, however, we assume that the molecule is distorted and that measurements were made on the ordered phase, we are at a loss to explain the discrepancy of $R \cdot \ln 2$ that would now exist between the spectroscopic and third-law values. Vibrational anharmonicities have not been considered in the spectroscopic entropy, but would not be expected to contribute more than $0.5 \mathrm{cal}$ mole ${ }^{-1 .{ }^{\circ}} \mathrm{K}^{-1}$ at $350^{\circ} \mathrm{K}$.

Two possibilities are, therefore, consistent with the observed quantities; either (a) the molecule is undistorted, or

(b) the molecule is distorted to $D_{3 d}$ symmetry and the disordered phase persisted to at least $5^{\circ} \mathrm{K}$.

We do not regard this latter possibility $(b)$ as likely: the small difference between the molecular orientations postulated by Jellinek $\left(60^{\circ}\right.$ rotation about the main symmetry axis) is such a small perturbation that it is unlikely to be "frozen in". The thermodyna- 
mic evidence, then, favors a symmetric molecule in which the benzene rings are not distorted. This is in keeping with X-ray structures reported by Bailey and Dahl for (hexamethylbenzene)chromium tricarbonyl ${ }^{20}$ and benzenechromium tricarbonyl ${ }^{21}$. In these molecules, the benzene rings possess full hexagonal symmetry, even though three-fold distortion might be encouraged by the trigonal chromium tricarbonyl moiety. A low temperature $\left(100^{\circ} \mathrm{K}\right) \mathrm{X}$-ray study of the structure of bis(benzene)chromium by Keulen and Jellinek ${ }^{24}$ failed to disclose a three-fold distortion, and a recent neutron diffraction study also indicates that the molecule is not distorted ${ }^{22}$. It should further be noted that there is as yet no firm experimental basis for the value for the $E_{u}^{-}$mode, $v 26$, (Table 4). Determination of this mode in the gaseous phase is an obvious desideratum for the argument which depends critically on the less energetic modes.

\section{ACKNOWLEDGEMENT}

The authors are grateful for the continuing support of the Division of Research of the U.S. Atomic Energy Commission. They also thank Professor Stig Sunner, of the Thermochemical Laboratory at Lund, Sweden, for his interest in initiating the study, and M. J. Simeon for help in the experimental measurements. One of us (J.T.SA.) takes this opportunity to thank the H. H. Rackham School of Graduate Studies of the University of Michigan for predoctoral fellowship support.

\section{REFERENCES}

1 E. O. Fischer and E. Weiss, Z. Anorg. Allg. Chem., 286 (1956) 142.

2 E. Ruch, Ber. Jahrestagung Chem. Ges. DDR, Leipzig (1959) 125.

3 F. JELLINEK, Nature, 187 (1960) 871.

4 F. A. Cotton, W. A. Dollase and J. S. Wood, J. Amer. Chem. Soc., 85 (1963) 1543.

5 F. Jellinek, J. Organometal. Chem., 1 (1963) 43.

6 E. O. FisCHER, Inorganic Synthesis, VI, Wiley, New York, 1960, p. 132.

7 E. F. Westrum, Jr., J. Chem. Educ., 39 (1962) 443.

8 J. W. Edwards AND G. L. Kington, Trans. Faraday Soc., 58 (1962) 1323.

9 G. W. Thomson, in A. Weissberger (Ed.), Physical Methods of Organic Chemistry, Vol. 1, Interscience, New York, 1959, p. 460.

10 M. KNudSen, Arn. Phys. (Leipzig), 28 (1909) 75.

11 J. W. HiBY AND M. PAHL, $Z$. Naturforsch., $A, 7$ (1952) 542.

12 P. C. Carman, Flow of Gases Through Porous Media, Butterworths, London, 1956, p. 67.

13 J. F. Cordes And S. SChreiner, Z. Anorg. Allg. Chem., 299 (1959) 87.

14 E. O. Fischer ANd S. SChreiner, Chem. Ber., 91 (1958) 2213.

15 D. C. BAIRD, Experimentation, Prentice-Hall, Englewood Cliffs, New Jersey, 1962, p. 186.

16 A. Haaland, Acta Chem. Scand., 19 (1965) 41.

17 H. P. Fritz, W. Lürtke, H. Stammkeich and R. Forniers, Spectrochim. Acta, 17 (1961) 1068.

18 R. G. SNYDER, Spectrochim. Acta, 15 (1959) 807.

19 J. H. Calloman, T. M. Dunn and I. M. Mills, Phil. Trans. Roy. Soc., Ser. A, 259 (1966) 499.

20 M. F. Barley and L. F. Dahl, Inorg. Chem., 4 (1965) 1298.

21 M. F. BaIley and L. F. Dahl, Inorg. Chem., 4 (1965) 1314.

22 G. Albrecht, E. Förster, D. Sippel, F. Eichorn and E. Kurras, Z. Chem., 8 (1968) 311.

23 J. T. S. ANDrews and E. F. Westrum, JR., J. Organometal. Chem., 17 (1969) 349.

24 E. Keulen and F. JellineK, J. Organometal. Chem., 5 (1966) 490. 